\title{
The Effectiveness of Emotion-Communication Skills Training on Cognitive Emotion Regulation, Parental Self-Efficacy and Child Acceptance in Mothers of Children with Learning Disabilities
}

\author{
Elham Fereydoni, Hossein Baqoli* Maryam Kouroshnia, Majid Barzegar \\ Department of Psychology, Marvdasht Branch, Islamic Azad University, Marvdasht, Iran \\ * Corresponding author’s Email: bhossein@gmail.com
}

\begin{abstract}
The aim of this study was to investigate the effect of emotional communication skills training on emotion regulation, parental self-efficacy and child acceptance in mothers of children with special learning disabilities. The statistical population of this study consisted of all mothers of students with special learning disabilities. Sampling method was accessible in that the participants were selected from mothers of children with learning disabilities who referred to clinics under the supervision of education in Shiraz. Of the 32 selected participants, 15 were assigned to the experimental group and 17 to the control group, randomly. After the pretest, the experimental group was trained in emotional communication skills in ten sessions, while the control group did not receive any specific intervention. Then, post-test was performed for both groups. Garnefski Cognitive Emotion Regulation Questionnaire (CERQ), Dumka Parental Self Agency Measure (PSAM) and Parental Acceptance Questionnaire (PAQ) were used to collect data. The results indicated that the experimental and control groups had significant differences in the variables of cognitive emotion regulation, parental self-efficacy and parental acceptance. In general, the findings supported the effectiveness of emotional-communication regulation skills training on parental characteristics and personality of parents.
\end{abstract}

Keywords: communication-emotional skills, special learning disorder, cognitive emotion regulation, parental self-efficacy, parental acceptance

\section{Introduction}

Learning can be considered a fundamental process as a result of which, a helpless creature, over time and in interaction with psychological and physical growth, reaches a person whose cognitive abilities and thinking power know no boundaries. Some people have problems in the normal process of learning. One group of these people are students with learning disabilities (Sobhigharamaleki, Abolghasemi, \& Dehghan, 2014). According to the Fifth edition of Diagnostic and Statistical Manual of Mental Disorders (DSM-5), learning disability has changed its name and nature to a specific learning disability so that the three mathematical disorders, reading disorder and writing disorder, each of which was previously considered an independent and separate disorder, are now considered as a specific area in a specific learning disorder. This disorder manifests itself in the form of learning difficulties and failure to acquire age-appropriate academic skills in the early years of education. These problems last for at least six months and are not related to mental disabilities or developmental or neurological or motor disorders. The prevalence of specific learning disabilities in reading, writing, and math is about 5-15\% in primary school children in different cultures, and its prevalence in adults is estimated at about $4 \%$ (American Psychiatric Association, 2013). 
Among family members, the mother is the first person who has a close relationship with the child, not only during the fetal period, but also in the afterlife, and among the many factors affecting human development in the child, the mother's personality and how she communicates is essential in the child development (Carnes-Holt, 2012).

Motherhood is a dynamic and stressful process, without any guidelines and dependent on culture and society. Achieving motherhood also requires knowledge, skills and motivation. Lack of knowledge, skills and motivation leads to deficits in maternal abilities and causes stress and anxiety (Jafarnejad, Azmoudeh, Mazloum, \& Reyhani, 2014). The presence of behavioral problems in children is an important predictor of maternal parental self-efficacy (Kuhn \& Carter, 2006) and causes parents, especially mothers, in their expectations and perceptions of how much they can be considered as a parent to act appropriately and effectively, and to what extent they are able to make a positive impact on their child's behavior, growth, and adjustment, and to feel high / low self-efficacy. Parental self-efficacy is an important cognitive structure that includes beliefs about success in parenting. Parental self-efficacy indicates how confident parents are in their ability to manage their child's problems. Low levels of parental self-efficacy often lead to depression and decreased satisfaction with parenting. Research has shown that parental self-efficacy is inversely related to children's behavioral problems (Jones \& Prinz, 2005).

Another important variable that mothers of exceptional children are involved with is cognitive regulation of emotion (Salimi, Mahdavi, Yeghaneh, Abedin, \& Hajhosseini, 2019). Managing and regulating emotion in individuals includes all conscious and unconscious strategies and helps the ability to understand emotions, adjust experience and express emotions. Any defect in emotion regulation can make a person vulnerable to mental disorders (Gravand \& Monshee, 2013). Emotional instability leads to inappropriate anger, chronic feelings of emptiness, mood swings, and frequent and intense responses to emotional stimuli. The emotional instability causes the mother to experience behavioral instability, poor control over her emotions, severe physiological arousal, and disruption of interpersonal relationships (Thghizadeh, Ghorbani, \& Saffarinia, 2015). Learning disabilities may affect a mother's acceptance of a child with these disorders, whereas in all children adopted by parents, they are more likely in adulthood to have behavioral adaptations (greater independence, higher self-esteem, low level aggression and more positive self-sufficiency) and children who are rejected by their parents are more likely to be associated with behavioral maladaptation (high level aggression, suicide, depression, antisocial behavior, dropout, and delinquency) into adulthood (Ronald P Rohner \& Khaleque, 2010). Parent-child interaction is a complex and multidimensional phenomenon and due to the interaction of several factors such as parental attitude and acceptance, how to manage and control behavior, sense of social competence and self-control, parenting knowledge and skills and self-confidence of parents in rearing children and creating an environment with minimal conflict are formed (Pourmohamadreza Tajrishi, Ashouri, Afrooz, Arjmandnia, \& Ghobari Bonab, 2015). Gaining a proper understanding and acceptance of children's behavior can predict parents 'empathy with children and their correct perception of parents' behavioral problems. Increasing parental acceptance and the child's perception of being 
accepted in relation to parents can be effective in reducing children's behavioral problems (Mostafavi, Shaeeri, Asghari Moghaddam, \& Mahmoudi Charaie, 2013). The ability to manage a mother's emotions is one of the factors that can be improved through education. Mothers who have a high ability to regulate emotion and understand their child's moods have more abilities in performing motherly duties (Golchin \& Hosseini-Nasab, 2013).

Behavioral scientists believe that one of the most effective programs that help people to have a better and healthier life is the communication skills training program. The purpose of this program is to help people to know themselves better and to establish appropriate and effective interpersonal relationships and to solve people's problems as best as possible. In the shadow of achieving such a goal, the sociopsychological ability of the individual increases. By improving the social abilities of individuals in a society, the level of mental health of the society can be increased and the occurrence of social harms can be prevented. Sadri Damirchi, Asadi Shishegaran, and Esmaili Ghazivaloii (2016), in a study entitled the effectiveness of social-emotional skills training on cognitive emotion regulation and social skills in children with special learning disabilities, concluded that there is a significant difference between the two groups in the components of cognitive emotion regulation (positive and negative). Also, there was a significant difference between the two groups in the components of social-emotional skills in increasing the use of positive emotional strategies and improving appropriate social skills, selfconfidence and relationships with peers. Ghaemi, Soltaninejad, and Khaje (2018), in a study entitled predicting quality of life based on cognitive emotion regulation strategies and communication skills in nurses, revealed a positive and significant relationship between cognitive emotion regulation strategies and communication skills with quality of life. The results showed that cognitive emotion regulation strategies and communication skills predict $48 \%$ of the variance of the psychological dimension and $39 \%$ of the variance of the physical dimension of quality of life. (Varasteh, Aslani, \& Amanelahi, 2017), in a study entitled the effectiveness of positive parenting program training on the quality of parent-child interaction, indicated that there was a significant difference between the experimental and control groups at least in one of the three factors including the proximity, dependence and overall positive relationship. Olivares-Olivares, Ortiz-González, and Olivares (2019) in their study investigated the effect of social skills training on social anxiety disorder. In this study that 108 adolescents participated with a diagnosis of generalized social anxiety, the subjects were randomly assigned to two groups (with and without social skills training). The results showed that social skills training reduces the rate of withdrawal from the intervention and increases the effectiveness of treatment programs.

According to the research literature and the results of previous studies, in this study, the effect of emotional-communication skills training in mothers of children with learning disabilities on parental self-efficacy, cognitive emotion regulation and parental acceptance was examined. Accordingly, the present study sought to answer the question of whether communication-emotional skills training can lead to increased self-efficacy, emotional regulation and parental acceptance in mothers of children with learning disabilities? 


\section{Material and Methods}

The research design was an experimental pre-test-post-test design with a control group. The statistical population of this study consisted of mothers of students with learning disabilities who referred to learning disability centers in Shiraz in the academic year of 2020. The sampling method was accessible and from the mothers of children with learning disabilities who referred to the clinics under the supervision of education in Shiraz, 32 people were selected who were randomly assigned to the control group ( $n=17)$ and the experimental group $(n=15)$. In addition, mothers who were absent for more than three sessions were excluded from statistical analysis, but were allowed to attend. The start of training sessions was subject to the timely attendance of all mothers, and a delay of more than 20 minutes was considered absenteeism. Also, to evaluate the validity of the educational program of the present study, several experts in this field were purposefully selected. The criteria for selecting these people was to have clinical and educational experiences in relation to the variables of study and to be familiar with the theoretical and hypothetical definitions of the structures. These people confirmed the validity of the training program. The following questionnaires were used to collect data.

Parental Self Agency Measure (PSAM): This questionnaire, developed in 1996 by Dumka et al., was used to assess overall levels of parenting self-efficacy. Dumka, Stoerzinger, Jackson, and Roosa (1996) reported internal consistency of this scale in English-speaking mothers with moderate economic status with a Cronbach's alpha coefficient of .70. In Iran, Talei, Tahmasian, and Vafai (2011) reported the Cronbach's alpha coefficient of this questionnaire as .70. In Jamali, Noroozi, and Tahmasebi (2013) research, the validity of the questionnaire has been estimated at a desirable level. In the present study, the reliability of this questionnaire was estimated to be .71 .

Porter Parental Acceptance Checklist (PPAC): The Porter Parental Acceptance Checklist (1954) is a self-administered questionnaire with 40 items that is used to measure parental acceptance as an indicator of parents' behavior and feelings toward their children. PPAC has four subscales: a) Respect for the child's feelings and the right to express those feelings. B) Approving the characteristics of the child. C) Recognizing the child's need for self-reliance and independence. D) Unconditional love and acceptance (Ronald P. Rohner \& Ali, 2020). Porter (1954) reported the reliability coefficient of this questionnaire by splitting method of .76 (Ronald P. Rohner \& Ali, 2020). The validity and reliability of this questionnaire in Iran was also examined by Seyed mousavi, Mazaheri, and Ghanbari (2016) and Cronbach's alpha coefficient for the whole questionnaire was reported to be .73. The validity of this scale was confirmed by at least three of the five expert judges for all items (Ronald P. Rohner \& Ali, 2020). In the present study, the reliability of this questionnaire was estimated to be .73 .

Garnefski Cognitive Emotion Regulation Questionnaire (CERQ): The Cognitive Emotion Regulation Questionnaire (CERQ) is a self-report tool developed by Garnefski and Kraaij (2007). The questionnaire consists of 36 items and measures cognitive emotion regulation strategies in response to life-threatening and stressful events in a five degree Likert scale and in terms of 9 subscales that each item scores between 1 (never) to 5 (always). Among the 9 subscales of the CERQ, the sum of the scores of five subscales of mental rumination, acceptance, self-blame, blaming others and catastrophic are considered as negative emotion regulation strategies and the sum of the scores of the four subscales of positive re-attention, re-attention to planning, positive evaluation and perspective are measured as 
positive emotion regulation strategies (Aldao, Nolen-Hoeksema, \& Schweizer, 2010). In a preliminary study of the validation features of this questionnaire in a sample of the general population $(n=365)$, Cronbach's alpha coefficients for subscales were calculated from .67 to .89 (Garnefski \& Kraaij, 2007). These coefficients, which were significant at the level .001, confirm the internal consistency of the CERQ. In Iran, the reliability coefficient of Cronbach's alpha for the subscale of negative emotion regulation strategies was .78 , for the subscale of positive emotion regulation strategies was .83 and for the whole scale was 0.81 . The coefficient of validity of this scale was 85 (Tabrizchi \& Vahidi, 2015). In the present study, the reliability of this questionnaire was estimated to be .77 .

At the beginning of this study, pre-test was taken from both of experimental and control groups (parents of children with learning disabilities who were trained in emotional communication skills and parents of children with learning disabilities who were not trained). The experimental group was then trained in emotional communication skills for ten sessions, but the control group did not receive any training. After training, post-test was taken from both groups. The hypotheses were tested by analysis of covariance. In the table 1, a summary of training sessions is presented.

Table 1. The summary of training session

\begin{tabular}{|c|c|}
\hline Sessions & Accomplishments \\
\hline $\begin{array}{l}\text { First } \\
\text { session }\end{array}$ & $\begin{array}{l}\text { Introduce, articulate goals and sessions, explain emotional communication skills and their role in family } \\
\text { health and well-being, schedule classes and answer their questions, provide basic information about children } \\
\text { with special learning disabilities and reasonable expectations from these children. }\end{array}$ \\
\hline $\begin{array}{l}\text { Second } \\
\text { session }\end{array}$ & $\begin{array}{l}\text { Familiarity with all kinds of emotions and feelings. } \\
\text { Exercise: Creating different situations and talking about the emotions and feelings related to that situation. }\end{array}$ \\
\hline $\begin{array}{l}\text { Third } \\
\text { session }\end{array}$ & $\begin{array}{l}\text { Emotion management and regulation training and its effect on mental and physical health, social relations } \\
\text { and responsibility. } \\
\text { Exercise: Creating situations that can be calmly expressed despite the presence of negative emotions. }\end{array}$ \\
\hline $\begin{array}{l}\text { Fourth } \\
\text { session }\end{array}$ & $\begin{array}{l}\text { Teaching self-awareness skills and its relationship with communication skills. } \\
\text { Exercise: Creating opportunities to assess your self-knowledge, strengths and weaknesses, knowledge of } \\
\text { your desires and beliefs. }\end{array}$ \\
\hline $\begin{array}{l}\text { Fifth } \\
\text { session }\end{array}$ & $\begin{array}{l}\text { Teaching how to communicate effectively including defining communication, communication components, } \\
\text { barriers to verbal and non-verbal communication. } \\
\text { Exercise: Practice to better understand the impact of proper and two-way communication with the child. }\end{array}$ \\
\hline $\begin{array}{l}\text { Sixth } \\
\text { session }\end{array}$ & $\begin{array}{l}\text { Teaching empathy and communication skills, measured and appropriate speaking, how to express the right } \\
\text { emotions in times of anger and failure. } \\
\text { Exercise: Practice dialogue with objective examples and present the difference with the time before the } \\
\text { training. }\end{array}$ \\
\hline $\begin{array}{l}\text { Seventh } \\
\text { session }\end{array}$ & $\begin{array}{l}\text { Active listening training, active listening barriers and the role of insight in communication. } \\
\text { Exercise: Practical practice of active listening and practical demonstration of its obstacles. }\end{array}$ \\
\hline $\begin{array}{l}\text { Eighth } \\
\text { session }\end{array}$ & $\begin{array}{l}\text { Familiarity with different types of communication patterns (assertive, aggressive and passive). } \\
\text { Exercise: Demonstrate all three patterns. }\end{array}$ \\
\hline $\begin{array}{l}\text { Ninth } \\
\text { session }\end{array}$ & $\begin{array}{l}\text { Teaching assertiveness skills and their relationship to communication skills } \\
\text { Exercise: Provide a model for the difference between assertiveness and aggression. }\end{array}$ \\
\hline $\begin{array}{l}\text { Tenth } \\
\text { session }\end{array}$ & Answering all the questions, summarizing the sessions, discussing during the session and taking the exam. \\
\hline
\end{tabular}

Note: Each of the above sessions was held for 90 minutes for the members of the experimental group. 


\section{Results}

Table 2 presents descriptive statistics of the pre-test and post-test scores of the research variables in the experimental and control groups. In table 3, the results of the Kolmogorov-Smirnov test to test the assumption of normality was exposed. The results of the normality test indicated that the distribution of scores of all dependent variables was normal.

Table 2. Descriptive statistics of the post-test scores of the research variables in the experimental and control groups

\begin{tabular}{|c|c|c|c|c|c|}
\hline \multirow[t]{2}{*}{ Variable } & \multirow[t]{2}{*}{ Phase } & \multicolumn{2}{|c|}{ Control group } & \multicolumn{2}{|c|}{ Experimental group } \\
\hline & & Mean & SD & Mean & $\mathrm{SD}$ \\
\hline \multirow[t]{2}{*}{ Blame yourself } & Pre-test & 9.18 & 2.48 & 10.45 & 1.40 \\
\hline & Post-test & 10.18 & 2.32 & 8.50 & 2.87 \\
\hline \multirow[t]{2}{*}{ Acceptance } & Pre-test & 8.91 & 1.66 & 8.45 & 2.87 \\
\hline & Post-test & 11.91 & 2.51 & 9.14 & 3.86 \\
\hline \multirow[t]{2}{*}{ Rumination } & Pre-test & 11.18 & 2.17 & 10.64 & 3.15 \\
\hline & Post-test & 13.14 & 3.24 & 11.64 & 3.56 \\
\hline \multirow[t]{2}{*}{ Positive refocusing } & Pre-test & 11.36 & 2.42 & 10 & 3.34 \\
\hline & Post-test & 12.68 & 3.09 & 12.95 & 3.73 \\
\hline \multirow[t]{2}{*}{ Re-focus planning } & Pre-test & 12.04 & 2.61 & 11.32 & 3.09 \\
\hline & Post-test & 14.41 & 2.95 & 14.04 & 3.59 \\
\hline \multirow[t]{2}{*}{ Positive evaluation } & Pre-test & 11.18 & 2.56 & 10.86 & 2.93 \\
\hline & Post-test & 12.86 & 3.38 & 13 & 3.84 \\
\hline \multirow[t]{2}{*}{ A broader perspective } & Pre-test & 9.45 & 2.48 & 9.18 & 2.40 \\
\hline & Post-test & 11.82 & 3.16 & 12.18 & 3.42 \\
\hline \multirow[t]{2}{*}{ Catastrophic } & Pre-test & 9.77 & 2.33 & 8.45 & 2.89 \\
\hline & Post-test & 10.77 & 2.99 & 10.27 & 4.16 \\
\hline \multirow[t]{2}{*}{ Blame others } & Pre-test & 9.04 & 2.36 & 8.36 & 2.92 \\
\hline & Post-test & 9.91 & 2.26 & 9.14 & 3.37 \\
\hline \multirow[t]{2}{*}{ Parental Self efficacy } & Pre-test & 25,68 & 5,91 & 26,62 & 6,07 \\
\hline & Post-test & 28,41 & 6,25 & 34,27 & 7,86 \\
\hline \multirow[t]{2}{*}{ Respect for the feelings and rights } & Pre-test & 10.95 & 2.15 & 9.23 & 2.89 \\
\hline & Post-test & 11.04 & 2.38 & 11.73 & 2.76 \\
\hline \multirow[t]{2}{*}{ Approve the features } & Pre-test & 9.14 & 2.01 & 9.50 & 1.50 \\
\hline & Post-test & 9.50 & 2.04 & 11.54 & 1.87 \\
\hline \multirow[t]{2}{*}{ Recognize the need for self-reliance } & Pre-test & 6.77 & 1.87 & 9.95 & 1.79 \\
\hline & Post-test & 7.18 & 1.65 & 8.41 & 2.36 \\
\hline \multirow[t]{2}{*}{ Unconditional acceptance } & Pre-test & 8.68 & 1.70 & 8.68 & 2.36 \\
\hline & Post-test & 9.27 & 1.64 & 10.04 & 2.17 \\
\hline
\end{tabular}


Table 2. The results of the Kolmogorov-Smirnov and Shapiro-Wilk test of normality

\begin{tabular}{|c|c|c|c|c|c|}
\hline \multirow[t]{2}{*}{ Variable } & \multirow[t]{2}{*}{ Group } & \multicolumn{2}{|c|}{ Normality test } & \multicolumn{2}{|l|}{$p$} \\
\hline & & $\mathrm{K}-\mathrm{S}$ & S-W & $\mathrm{K}-\mathrm{S}$ & S-W \\
\hline \multirow[t]{2}{*}{ Blame yourself } & Experimental & .18 & .95 & .07 & .37 \\
\hline & Control & .12 & .89 & .20 & .14 \\
\hline \multirow[t]{2}{*}{ Acceptance } & Experimental & .19 & .93 & .14 & .30 \\
\hline & Control & .24 & .81 & .20 & .09 \\
\hline \multirow[t]{2}{*}{ Rumination } & Experimental & .19 & .93 & .14 & .30 \\
\hline & Control & .24 & .81 & .20 & .09 \\
\hline \multirow[t]{2}{*}{ Positive refocusing } & Experimental & .12 & .16 & .20 & .20 \\
\hline & Control & .19 & .92 & .14 & .19 \\
\hline \multirow[t]{2}{*}{ Re-focus planning } & Experimental & .16 & .91 & .16 & .35 \\
\hline & Control & .15 & .92 & .19 & .32 \\
\hline \multirow[t]{2}{*}{ Positive evaluation } & Experimental & .14 & .92 & .20 & .07 \\
\hline & Control & .18 & .94 & .07 & .26 \\
\hline \multirow[t]{2}{*}{ A broader perspective } & Experimental & .15 & .95 & .20 & .37 \\
\hline & Control & .13 & .96 & .20 & .55 \\
\hline \multirow[t]{2}{*}{ Catastrophic } & Experimental & .12 & .93 & .20 & .14 \\
\hline & Control & .19 & .95 & .16 & .30 \\
\hline \multirow[t]{2}{*}{ Blame others } & Experimental & .14 & .90 & .20 & .38 \\
\hline & Control & .18 & .94 & .09 & .43 \\
\hline \multirow[t]{2}{*}{ Parental Self efficacy } & Experimental & .22 & .85 & .13 & .07 \\
\hline & Control & .18 & .89 & .15 & .14 \\
\hline \multirow[t]{2}{*}{ Respect for the feelings and rights } & Experimental & .22 & .85 & .13 & .07 \\
\hline & Control & .18 & .89 & .15 & .14 \\
\hline \multirow[t]{2}{*}{ Approve the features } & Experimental & .20 & .89 & .10 & .06 \\
\hline & Control & .17 & .95 & .20 & .46 \\
\hline \multirow[t]{2}{*}{ Recognize the need for self-reliance } & Experimental & .13 & .94 & .20 & .40 \\
\hline & Control & .20 & .94 & .12 & .45 \\
\hline \multirow[t]{2}{*}{ Unconditional acceptance } & Experimental & .17 & .94 & .20 & .37 \\
\hline & Control & .23 & .85 & .15 & .16 \\
\hline
\end{tabular}

The following hypotheses were tested in the current study:

Hypothesis 1: Communication-emotional skills training is effective on cognitive emotion regulation in mothers of children with learning disabilities.

Hypothesis 2: Communication-emotional skills training is effective on parental self-efficacy in mothers of children with learning disabilities.

Hypothesis 3: Communication-emotional skills training is effective on parental acceptance components in mothers with children with learning disabilities. 
In order to investigate the effect of communication-emotional skills training on cognitive emotion regulation in mothers of children with learning disabilities, multivariate analysis of covariance was used.

Table 3. Results of analysis of covariance to compare the experimental and control groups in cognitive emotion regulation strategies

\begin{tabular}{|l|l|l|l|l|l|l|l|}
\hline Source & DVs & SS & DF & MS & F & P & Eta \\
\hline \multirow{5}{*}{ Group } & Blame yourself & 74.04 & 1 & 74.04 & 34.31 & .001 & .53 \\
\cline { 2 - 8 } & Acceptance & 10.63 & 1 & 10.63 & 8.21 & .008 & .21 \\
\cline { 2 - 8 } & Rumination & 6.05 & 1 & 6.05 & 7.45 & .011 & .20 \\
\cline { 2 - 8 } & Positive refocusing & 9.72 & 1 & 9.72 & 16.58 & .001 & .36 \\
\cline { 2 - 8 } & Re-focus planning & 14.56 & 1 & 14.56 & 19.80 & .001 & .40 \\
\cline { 2 - 8 } & Positive evaluation & 88.90 & 1 & 88.90 & 47.77 & .001 & .61 \\
\cline { 2 - 8 } & A broader perspective & 54.70 & 1 & 54.70 & 25.82 & .001 & .46 \\
\cline { 2 - 8 } & Catastrophic & 68.58 & 1 & 68.58 & 6.19 & .018 & .17 \\
\cline { 2 - 8 } & Blame others & 140.55 & 1 & 140.55 & 37.30 & .001 & .55 \\
\cline { 2 - 8 } & Parental Self efficacy & 32.61 & 1 & 32.61 & 4.32 & .05 & .13 \\
\cline { 2 - 7 } & Respect for the feelings and rights & 28.55 & 1 & 28.55 & 8.78 & .009 & .28 \\
\cline { 2 - 7 } & Approve the features & 17.47 & 1 & 17.47 & 6.21 & .021 & .23 \\
\cline { 2 - 7 } & Recognize the need for self-reliance & 33.43 & 1 & 33.43 & 10.54 & .002 & .32 \\
\cline { 2 - 7 } & Unconditional acceptance & 17.05 & 1 & 17.05 & 6.10 & .024 & .20 \\
\hline
\end{tabular}

According to Table 3, all research hypotheses were confirmed. Accordingly, communication-emotional skills training has been significantly effective on all cognitive regulation strategies, parental self-efficacy and parental acceptance components in mothers of children with learning disabilities.

\section{Discussion}

Hypothesis 1: Communication-emotional skills training is effective on cognitive emotion regulation in mothers of children with learning disabilities.

The results revealed that communication-emotional skills training has been significantly effective on cognitive regulation of emotion in mothers of children with learning disabilities. Analysis of the means indicated that the experimental group had a higher mean in performing the post-test of cognitive emotion regulation than the control group. Therefore, the first hypothesis of the study was confirmed.

This finding is consistent with the results of previous studies. Denault and Déry (2015) showed in their research that emotional skills training increases social adequacy, self-awareness skills, empathy, interpersonal communication, coping with emotions, making the right decisions and solving social problems. Ratcliffe, Wong, Dossetor, and Hayes (2014) have also concluded that communicationemotional skills training increases emotional skills and social competencies and overall mental health. Lau, Chan, Li, and Au (2010) indicated that the behavioral strategies used for families of children with 
disabilities was effective on problem-solving, achieving personal goals, cognitive reconstruction, observation of thoughts and feelings and relaxation.

In line the previous study, the inability to develop emotional skills in a timely and correct manner can threaten a person's physical and mental health and challenge the person's adaptation in interaction with other people (Pugliesi, 1999). Failure to regulate and manage emotions leads to a little control over the situation and evaluating the situation as stressful and negative and reacting abnormally with the occurrence of negative emotions. Evidence suggests that negative consequences such as anxiety, depression, suicide, social dysfunction, and other cognitive impairments are associated with repression and inhibition of emotion expression (Gross, 2018). In addition, emotional inhibition is associated with decreased cognitive-social abilities and interpersonal adjustment (Sun \& Lau, 2018).

In explaining this finding, it can be said that many components of emotional intelligence, understanding and comprehending the emotions of others, regulating and controlling emotions, monitoring the stress, and other abilities and skills that are associated with emotional intelligence, are the basis for having the emotional-communication skills.

Hypothesis 2: Communication-emotional skills training is effective on parental self-efficacy in mothers of children with learning disabilities.

The results showed that communication-emotional skills training had a significant effect on parental self-efficacy in mothers of children with learning disabilities. Analysis of the means showed that the experimental group had a higher mean in the post-test of parental self-efficacy than the control group. Therefore, the second hypothesis of the study was confirmed. Wittkowski, Dowling, and Smith (2016) indicated that communication-emotional skills group training is effective on parental self-efficacy. Also the findings of this research is in line with the previous studies (Davis, 2018; Noyan Erbaș, Özcebe, \& Cak Esen, 2021; Wittkowski et al., 2016).

Many mothers of children with disabilities blame themselves for their child's current problems or think that their child has deliberately chosen to abuse them (Sanders, 2012). Better self-efficacy seems to require communication skills. Interpersonal communication is the basis of human identity and the basis of his connection with others. Effective communication leads to people flourishing and improving the quality of interactions. At the same time, inefficient and ineffective communication hinders human growth and prosperity and severely destroys relationships. Numerous studies also have shown that communication skills are teachable and the resulting changes are sustained over time (Silverman, Kurtz, \& Draper, 2016). Evidence shows that children's behavioral and developmental problems have a significant effect on reducing parental self-efficacy (Segrin, McNelis, \& Swiatkowski, 2016).

The feeling of self-efficacy requires knowledge and information about effective methods of child care, interaction and communication with him. Self-efficacy is involved in a child's development both directly and by influencing parenting styles. Therefore, trying to improve and promote this feature in the mother, helps a lot in the development of the child. Abarashi, Tahmassian, Mazaheri, Panaghi, and Mansoori (2014) showed that increasing maternal self-efficacy is associated with improving the quality of mother- 
child interactions. In fact, strengthening parenting skills and teaching skills to communicate with the child can play a moderating role in childhood behavioral problems and parental self-efficacy.

Hypothesis 3: Communication-emotional skills training is effective on parental acceptance components in mothers with children with learning disabilities.

The results showed that communication-emotional skills training had a significant effect on parental acceptance in mothers of children with learning disabilities. Analysis of the means showed that the experimental group had a higher mean in the post-test of parental acceptance compared to the control group. Therefore, the third hypothesis of the study was confirmed. The results are in line with the findings of earlier studies (Abarashi et al., 2014; Jafarnejad et al., 2014). Amanollahi, Shadfar, and Aslani (2018) in a study aimed at investigating the effectiveness of parent-child relationship therapy on parenting stress and parental acceptance of primary school children concluded that parent-child relationship therapy is an effective program to reduce parenting stress and increase parental acceptance. Parent-child relationships are the focus of child pathology because inappropriate interactions can cause emotional and behavioral disorders in children and adolescents, so that behavioral and emotional disorders in children can lead to marital problems (Kaplan, Cortina, Ruark, LaPort, \& Nicolaides, 2014). Teaching parents emotional and communication skills reduces the use of negative emotional strategies to deal with children's behavioral problems and stressful situations, and this will lead to their emotional health and academic success in the future (McLaughlin, Hatzenbuehler, Mennin, \& Nolen-Hoeksema, $\underline{2011})$.

Teaching emotional communication skills helps mothers to be calm, positive, and non-impulsive in the face of the child's behaviors, and instead of feeling helpless or immature reactions to the child, to devise and create different solutions and be able to avoid entering the vicious cycle of inappropriate parentchild interactions (Eisvandi, Gorji, \& Niknejadi, 2015).

The present study has been associated with some limitations that should be considered in generalizing the findings. The large number of questionnaires, the use of self-report tools and lack of control over interference variables such as education level and social and economic status of participants are the most important of these limitations. Interested researchers are suggested to use other methods of data collection in future research such as interviews and repeat the present research in examples from other cities and regions of the country. Based on the research findings and considering the importance of mother-child interaction and the effect of maternal care on child development, it is suggested that along with other medical care of pregnant mothers, holding emotional communication skills training sessions to prepare mothers in proper communication with the child during infancy should be considered.

Conflict of interest: The authors state no conflict of interest in the study.

Financial sponsor: The authors acknowledge that they have not received any financial support for all stages of the study, writing and publication of the paper. 
Acknowledgment: We hereby appreciate all the participants of the study as well as all those participating in the implementation of this project.

\section{References}

Abarashi, Z., Tahmassian, K., Mazaheri, M. A., Panaghi, L., \& Mansoori, N. (2014). Parental self-efficacy as a determining factor in healthy mother-child interaction: a pilot study in Iran. Iranian journal of psychiatry and behavioral sciences, 8(1), 19-25.

Aldao, A., Nolen-Hoeksema, S., \& Schweizer, S. (2010). Emotion-regulation strategies across psychopathology: A meta-analytic review. Clinical psychology review, 30(2), 217-237.

Amanollahi, A., Shadfar, A., \& Aslani, K. (2018). Effectiveness of Child Parent Relationship Therapy on Parental Acceptance and Decreasing of disruptive behaviors. Counseling Culture and Psycotherapy, 9(36), 163-184.

American Psychiatric Association, A. (2013). Diagnostic and statistical manual of mental disorders (DSM-5®): American Psychiatric Pub.

Carnes-Holt, K. (2012). Child-parent relationship therapy for adoptive families. The Family Journal, 20(4), 419426.

Davis, S. (2018). Parent Training for Children with Autism Spectrum Disorders: The Effects on Parent Stress Levels, Parents' Self-Efficacy towards Parenting, and Child Problem Behaviors. Roosevelt University,

Denault, A.-S., \& Déry, M. (2015). Participation in organized activities and conduct problems in elementary school: The mediating effect of social skills. Journal of Emotional and Behavioral Disorders, 23(3), 167-179.

Dumka, L. E., Stoerzinger, H. D., Jackson, K. M., \& Roosa, M. W. (1996). Examination of the cross-cultural and cross-language equivalence of the parenting self-agency measure. Family Relations, 45(2), 216-222.

Eisvandi, M., Gorji, Y., \& Niknejadi, F. (2015). Effectiveness of Emotional Intelligence on Increasing the Psychological Dimension of Quality of Life of Mothers of Educable Mentally Retarded Children in Esfahan in. UCT Journal of Social Sciences and Humanities Research, 3(1), 29-31.

Garnefski, N., \& Kraaij, V. (2007). The cognitive emotion regulation questionnaire. European Journal of Psychological Assessment, 23(3), 141-149.

Ghaemi, F., Soltaninejad, M., \& Khaje, F. (2018). The Prediction of Quality of life Based on Cognitive Emotion Regulation Strategies and Communication Skills in Female Nurses. Iranian Journal of Psychiatric Nursing, 6(5), 50-56.

Golchin, R., \& Hosseini-Nasab, S. D. (2013). A comparison of children's behavior problems among mothers with high and low emotional intelligence. Journal of Instruction and Evaluation, 6(24), 13-24.

Gravand, P., \& Monshee, A. (2013). The effectiveness of teaching forgiveness based on Enright model and enriching the relationships on mental wellbeing and life quality of dissatisfied women from their marital life in the city of Khoram Abad. Middle Eastern Journal of Disability Studies, 2(12), 29-36.

Gross, J. T. (2018). Expressive Suppression In Middle Childhood: Links With Negative Emotion, Physiology, And Prosocial Behavior. University of Maryland Maryland. Retrieved from http://hdl.handle.net/1903/20731 
Jafarnejad, F., Azmoudeh, E., Mazloum, S. R., \& Reyhani, T. (2014). The Effect of Self-Efficacy Training Package on Maternal Self-Confidence of Primiparous Women in Infant Care. The Iranian Journal of Obstetrics, Gynecology and Infertility, 17(104), 18-28. doi:10.22038/ijogi.2014.3021

Jamali, M., Noroozi, A., \& Tahmasebi, R. (2013). Factors affecting academic self-efficacy and its association with academic achievment among students of Bushehr University Medical Sciences 2012-13. Iranian Journal of Medical Education, 13(8), 629-641.

Jones, T. L., \& Prinz, R. J. (2005). Potential roles of parental self-efficacy in parent and child adjustment: A review. Clinical psychology review, 25(3), 341-363.

Kaplan, S., Cortina, J., Ruark, G., LaPort, K., \& Nicolaides, V. (2014). The role of organizational leaders in employee emotion management: A theoretical model. The Leadership Quarterly, 25(3), 563-580.

Kuhn, J. C., \& Carter, A. S. (2006). Maternal self-efficacy and associated parenting cognitions among mothers of children with autism. American Journal of Orthopsychiatry, 76(4), 564-575.

Lau, W.-y., Chan, C. K.-y., Li, J. C.-h., \& Au, T. K.-f. (2010). Effectiveness of group cognitive-behavioral treatment for childhood anxiety in community clinics. Behaviour research and therapy, 48(11), 1067-1077.

McLaughlin, K. A., Hatzenbuehler, M. L., Mennin, D. S., \& Nolen-Hoeksema, S. (2011). Emotion dysregulation and adolescent psychopathology: A prospective study. Behaviour research and therapy, 49(9), 544-554.

Mostafavi, S., Shaeeri, M. R., Asghari Moghaddam, M. A., \& Mahmoudi Charaie, J. (2013). Effectiveness Of Educating Play Therapy Based On Child Parent Relationship Therapy (Cprt) According Landreth Model To Mothers On Reducing Child Behavioral Problems. CLINICAL PSYCHOLOGY \& PERSONALITY (DANESHVAR RAFTAR), 19(7), 33-42.

Noyan Erbaş, A., Özcebe, E., \& Cak Esen, T. (2021). Investigation of the effect of Hanen's "More Than Words" on parental self-efficacy, emotional states, perceived social support, and on communication skills of children with ASD. Logopedics Phoniatrics Vocology, 46(1), 17-27.

Olivares-Olivares, P. J., Ortiz-González, P. F., \& Olivares, J. (2019). Role of social skills training in adolescents with social anxiety disorder. International journal of clinical and health psychology, 19(1), 41-48.

Pourmohamadreza Tajrishi, M., Ashouri, M., Afrooz, G. A., Arjmandnia, A. A., \& Ghobari Bonab, B. (2015). The Effectiveness Of Positive Parenting Program (Triple-P) Training On Interaction Of Mother-Child With Intellectual Disability. ARCHIVES OF REHABILITATION (JOURNAL OF REHABILITATION), 16(2), 128136.

Pugliesi, K. (1999). The consequences of emotional labor: Effects on work stress, job satisfaction, and well-being. Motivation and Emotion, 23(2), 125-154.

Ratcliffe, B., Wong, M., Dossetor, D., \& Hayes, S. (2014). Teaching social-emotional skills to school-aged children with Autism Spectrum Disorder: A treatment versus control trial in 41 mainstream schools. Research in Autism Spectrum Disorders, 8(12), 1722-1733.

Rohner, R. P., \& Ali, S. (2020). Parental Acceptance-Rejection Questionnaire (PARQ). In V. Zeigler-Hill \& T. K. Shackelford (Eds.), Encyclopedia of personality and individual differences (pp. 3425-3427). Cham: Springer International Publishing.

Rohner, R. P., \& Khaleque, A. (2010). Testing central postulates of parental acceptance-rejection theory (PARTheory): A meta-analysis of cross-cultural studies. Journal of Family Theory \& Review, 2(1), 73-87. 
Sadri Damirchi, E., Asadi Shishegaran, S., \& Esmaili Ghazivaloii, F. (2016). Effectiveness of Emotion Regulation Training on Cognitive Emotional Regulation, Loneliness and Social Intimacy in Women with Addicted Spouse. Quarterly Journal of Social Work, 5(2), 37-46.

Salimi, M., Mahdavi, A., Yeghaneh, S. S., Abedin, M., \& Hajhosseini, M. (2019). The effectiveness of group based acceptance and commitment therapy (ACT) on emotion cognitive regulation strategies in mothers of children with autism spectrum. Maedica, 14(3), 240-246.

Sanders, M. R. (2012). Development, evaluation, and multinational dissemination of the Triple P-Positive Parenting Program. Annual review of clinical psychology, 8, 345-379.

Segrin, C., McNelis, M., \& Swiatkowski, P. (2016). Social skills, social support, and psychological distress: A test of the social skills deficit vulnerability model. Human Communication Research, 42(1), 122-137.

Seyed mousavi, P. s., Mazaheri, M., \& Ghanbari, S. (2016). Psychometric Properties of Parental and Intimate Partner Acceptance-Rejection in Students. Iranian Journal of Psychiatry and Clinical Psychology, 21(4), 327337.

Silverman, J., Kurtz, S., \& Draper, J. (2016). Skills for communicating with patients: crc press.

Sobhigharamaleki, N., Abolghasemi, A., \& Dehghan, H. (2014). Comparison Of A, B, C And D Brain Quadrants Dominance In Normal Students And Students With Learning Disabilities. JOURNAL OF LEARNING DISABILITIES, 3(4), 59-79.

Sun, M., \& Lau, A. S. (2018). Exploring cultural differences in expressive suppression and emotion recognition. Journal of cross-cultural psychology, 49(4), 664-672.

Tabrizchi, N., \& Vahidi, Z. (2015). Comparing emotional regulation, mindfulness and psychological well-being in mothers of students with and without learning disabilities. JOURNAL OF LEARNING DISABILITIES, 4(4), 21-35.

Talei, A., Tahmasian, K., \& Vafai, N. (2011). Effectiveness of positive parenting program training on mothers' parental self-efficacy. Journal of Family Research, 7(3), 311-323.

Thghizadeh, M., Ghorbani, T., \& Saffarinia, M. (2015). Effectiveness of emotion regulation techniques of dialectical behavior therapy on emotion regulation strategies in women with borderline personality disorder and substance abuse disorder: Multiple Baseline Design. Journal of Research in PsychologicalHealth, 9(3), 66-73.

Varasteh, M., Aslani, K., \& Amanelahi, A. (2017). Effectiveness of positive parenting program training on parentchild interaction quality. Counseling Culture And Psychotherapy, 7(28), 183-201.

Wittkowski, A., Dowling, H., \& Smith, D. M. (2016). Does engaging in a group-based intervention increase parental self-efficacy in parents of preschool children? A systematic review of the current literature. Journal of Child and Family Studies, 25(11), 3173-3191. 